\title{
Thiamphenicol in the treatment of chancroid in men
}

\author{
A S LATIF \\ From the City Health Department and the Department of Medicine, University of Zimbabwe Medical School \\ Salisbury, Zimbabwe
}

SUMMARY Thiamphenicol was used to treat 547 men with chancroid. An oral dose of $2 \cdot 5 \mathrm{~g}$ was $\vec{\odot}$ given on the first day and a further dose of $1 \cdot 25 \mathrm{~g}$ a week later if the lesions had not healed. Eighty $\vec{\omega}$ seven $(15 \cdot 9 \%)$ patients defaulted from follow up and $23(4 \cdot 2 \%)$ had positive serological test results for syphilis. Of the remaining 437 patients, $27(6 \cdot 2 \%)$ failed to respond to treatment, $258 \%$. $(59 \%)$ were cured after the single dose, and $152(34 \cdot 8 \%)$ required a second dose. The overall cures rate was $93 \cdot 8 \%$.

\section{Introduction}

Thiamphenicol is a broad-spectrum antibiotic, has a bacteriostatic action against a wide range of Grampositive and Gram-negative bacteria and anaerobes, is closely related to chloramphenicol, and has few side effects. It has been used in the treatment of uncomplicated gonorrhoea in a single dose of $2.5 \mathrm{~g}$ with high cure rates. ${ }^{1}$ A single dose of $2.5 \mathrm{~g}$ of thiamphenicol has been found to be effective against syphilis during the incubation period. ${ }^{2}$

\section{Patients and methods}

Patients included in the trial were men who presented voluntarily with chancroid to the Mbare Sexually Transmitted Diseases Clinic in Harare, Salisbury.

\section{DIAGNOSTIC CRITERIA}

The diagnosis of chancroid was made by the clinical finding of painful, non-indurated, necrotic ulcers, exudates of which showed no Treponema pallidum on darkground microscopy but showed typical slender Gram-negative bacilli in small chains and clusters. The Venereal Disease Research Laboratory (VDRL) test and the $T$ pallidum haemagglutination assay (TPHA) were carried out on all patients at the time of the first visit and six weeks later. Of 1018 patients tested, 547 met the diagnostic criteria and were included in the study. Cultures for Haemophilus ducreyi and the Ito-Reenstierna intradermal tests were not carried out because of lack of facilities.

Address for reprints: Dr A S Latif, 14 Viscount Bend, Ridgeview, Belvedere, Salisbury, Zimbabwe

Accepted for publication 23 September 1981
TREATMENT AND FOLLOW-UP

After the detection of $H$ ducreyi in Gram-stainedo' smears of ulcer material the patients were given $2 \cdot 5 \%$ (10 capsules) of thiamphenicol to swallow at the clinic under supervision. They were asked to return after seven days and advised not to have sexualo intercourse nor take any alcohol till the sores hadN healed. They were also advised on simple personat hygiene, told to wash the genital area thoroughlyk with soap and water at least twice a day, and warne $\bar{\delta}$ not to apply any form of ointment locally.

If at the end of seven days the ulcers showed sign $\$$ of healing and were no longer painful or tender o examination with a cottonwool-tipped swab th patient was given no further treatment but asked toreturn in a further week's time. If the ulcers were sti painful the patient was given $1 \cdot 25 \mathrm{~g}$ of thiamphenicold to take at the clinic and was asked to return a wee later.

If at the third visit the ulcers had healed or showe signs of healing no further treatment was given an the patient was asked to return after two weeks for examination. If, however, the ulcers had still not healed, treatment failure was assumed and the patient was given co-trimoxazole $800 \mathrm{mg}$ three time

daily for seven days.
At the end of six weeks blood was taken for VDR and TPHA tests. Exudates from ulcers were examined by darkfield microscopy, and Gramw stained smears of ulcer material were examined for ducreyi at each visit.

\section{Results}

One thousand and eighteen patients with genita市 ulcers were examined. In $547(53 \cdot 7 \%)$ patient 
exudates from ulcers showed organisms resembling $H$ ducreyi. Of these, $87(15 \cdot 9 \%)$ defaulted from follow up (63 after the first visit and 24 after attending twice). Twenty-three $(4 \cdot 2 \%)$ had a posititive TPHA result, and of these, 18 also had a positive VDRL test result.

Inguinal buboes were present in 240 patients; in $225(51 \cdot 5 \%)$ they were unilateral and in $15(3 \cdot 4 \%)$ bilateral.

Of those followed up fully, 258 (59\%) patients needed only the first dose of treatment and a further $152(34 \cdot 8 \%)$ were cured after the second dose. Twenty-seven $(6 \cdot 2 \%)$ patients failed to respond to treatment.

In the patients with buboes the size of the swelling had greatly subsided at the end of two weeks, although some induration was still palpable at the end of six weeks.

\section{Discussion}

Chancroid is the commonest form of STD seen among male patients attending STD clinics in Salisbury. ${ }^{3}{ }^{4}$ Patients with chancroid are usually treated with a seven-day course of tetracycline or intramuscular streptomycin. Prolonged courses of treatment are often necessary and hence patients commonly default. Single-dose regimens for the treatment of trichomoniasis, uncomplicated gonococcal urethritis, and early syphilis are now generally recommended. ${ }^{5}$ No satisfactory single-dose treatment regimens are at present available for the treatment of chancroid. This trial suggests that two large doses of thiamphenicol given a week apart may be of considerable value in the treatment of this infection.

I wish to thank Mr Graham Wright and Mr George Dempster of DATLABS, Sinoia Street, Salisbury, for supplying Urfamycin capsules used in this trial.

\section{References}

1. Siboulet A. Minute treatment of gonoccal urethritis of the male, Sem Ther 1965; 41:307.

2. Petzoldt D. Single-dose treatment of gonorrhoea with penicillin or thiamphenicol and effect on Treponema pallidum in experimental syphilis. Br J Vener Dis 1971; 47;377.

3. Latif AS. Sexually transmitted disease in clinic patients in Salisbury, Zimbabwe. Br J Vener Dis 1981;57:181-3.

4. Bingham JS. Zimbabwe: land of hope and...Br J Vener Dis 1981;57:184-6.

5. Schofield CBS. Sexually Transmitted Diseases, 3rd ed. Edinburgh: Churchill Livingstone, 1979. 